\title{
A Study on Renewable Energy as a Sustainable Alternative for Ensuring Energy Security in Bangladesh and Related Socio-Economic Aspects
}

\author{
Dewan Mowdudur Rahman ${ }^{1, *}$, Navid Bin Sakhawat ${ }^{2}$, Riasad Amin ${ }^{1}$, and Faisal Ahmed \\ 1 Department of EECE, Military Institute of Science and Technology, Dhaka, Bangladesh \\ 2 Department of EEE, BRAC University, Dhaka, Bangladesh \\ 3 Department of CIT, Islamic University of Technology, Gazipur, Bangladesh \\ E-mail: mowdudur@gmail.com*
}

\begin{abstract}
Deficiency in energy sector is a major problem, which can hinder the development workflow of any country. Being the eighth most populated country in the world with a total electricity generation of only about $5000 \mathrm{MW}$ and consumption of 146 $\mathrm{kWh}$ per capita, Bangladesh is one of the most electricity-deprived countries around the globe. In addition, absence of adequate investment and mass people awareness is a major problem in this country. Therefore, it would be very difficult to achieve overall progress without ensuring energy security by utilizing the promising renewable energy sources. In order to achieve the Millennium Development Goal (MDG), it is must for a third world country like Bangladesh to address the issue of energy deficiency promptly. In this context, renewable energy is the sustainable solution of energy security as well as social, environmental and economical problems. This paper summarizes the current energy scenario of Bangladesh, impacts of pollution from conventional energy sources, prospects of renewable energy development, and estimates the total investment required in Bangladesh to promote renewable energy sector by the year 2020 .
\end{abstract}

Keywords: Renewable energy, energy scenario in Bangladesh, climate change effects, required investment in Bangladesh.

ENGINEERING JOURNAL Volume 16 Issue 2

Received 3 December 2011

Accepted 22 January 2012

Published 1 April 2012

Online at http://www.engj.org

DOI:10.4186/ej.2012.16.2.47 


\section{Introduction}

Bangladesh, as an independent country, has already passed about forty years. However, we are still a long way behind to emerge as a developed nation from a developing one. The people of this country are still fighting in order to obtain energy security as well as looking for a suitable solution to ensure all the basic needs, such as education, employment, and health-care facilities. Energy consumption is an important quantitative measure that provides a rough estimation of the level of progress achieved within a civilization and industrial activities of a nation. However, with its 142 million people [1], Bangladesh has not yet ensured 100\% electricity accessibility. Only 20\% people are now grid connected [2] and only $42 \%$ people have electricity accessibility [3]. Per capita electricity consumption is only $146.5 \mathrm{kWh}$ in Bangladesh, whereas in India, it is $480.5 \mathrm{kWh}$ and in Pakistan, it is $456.2 \mathrm{kWh}$ [4]. For developed countries, the average per capita electricity consumption is $8009.5 \mathrm{kWh}$ and for developing countries, it is $1169 \mathrm{kWh}$. For any high-income country, the average per capita electricity consumption is $9789 \mathrm{kWh}$ and for any low-income country, it is $392.4 \mathrm{kWh}$ [4]. Thus, in every index Bangladesh is far more behind only because of poor electricity generation and consumption. Therefore, it is mandatory to promote our power sector in order to ensure the development of this country. In this context, renewable energy would be a viable option to achieve energy security in Bangladesh. If we can boost up the renewable energy sector with proper investment and ambitious policy, only then we could possibly get energy security and able to eradicate all the problems in a sustainable way.

\section{Present Scenario of Energy Sector in Bangladesh}

Power generation in Bangladesh has been dependent on natural gas and still now, $79.331 \%$ of electricity is being produced from our gas reserve. However, our net remaining gas reserve (proven and probable) is only $13.53 \mathrm{Tcf}$ [5]. According to [6], present proven reserve of indigenous gas will be exhausted by 2030 . On the other hand, our coal reserve is only 2.7 billion tons [7]. The chart in Fig. 1 shows the percentage of electricity production in Bangladesh from various sources.

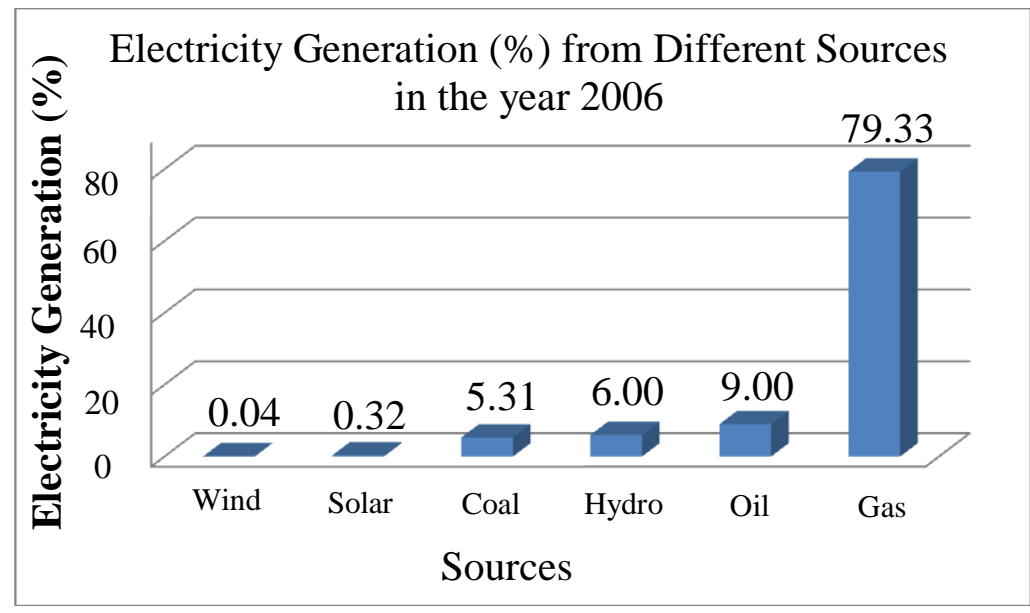

Fig. 1. Percentage of electricity generation in Bangladesh from different sources [8].

It can be observed that only $6.359 \%$ of electricity is coming from non-carbon sources (hydro, solar and wind) and $93.64 \%$ of energy is coming from hydrocarbon sources (gas, oil and coal) in Bangladesh. Whereas $80 \%$ of total energy demand comes from fossil fuel, the remaining $20 \%$ comes from nuclear and renewable sources throughout the world [9]. Though we have an agricultural based economy, it is a pity that we are keeping nothing left for future fertilizer production, where natural gas is the main raw material.

\section{Climate Change Effects}

The power sector of Bangladesh is responsible of emitting $40 \%$ of carbon dioxide $\left(\mathrm{CO}_{2}\right)$ gas $(15.24$ million tons), whereas $30 \%$ of $\mathrm{CO}_{2}$ emits from power sector throughout the world $[10,11]$. This emission of $\mathrm{CO}_{2}$ 
and other green house gases is responsible for temperature rising and global warming. Over the past 100 years, temperature has increased by 0.50 degree Celsius due to global warming. However, in the next 40 years, the temperature in Bangladesh is projected to rise by 1.5 to 2.00 degree Celsius [12, 13]. It is estimated that climate change could affect more than 70 million people of Bangladesh [14]. Agriculture is the largest sector of this country's economy that accounts for about $23.87 \%$ of the GDP [15]. However, rise in temperature of 4 degree Celsius would decrease the food grain production some $28 \%$ and $68 \%$ for rice and wheat, respectively [15]. Therefore, it is very clear that, the adverse effects of $\mathrm{CO}_{2}$ emission will be more intense for any low laying country like Bangladesh. This includes mass migration, famine and extreme poverty. Sulfur emission, resulting primarily from burning of fuel in conventional power plant to produce electricity are the main source of acid rain which damages crop, forest and can make lakes and rivers too acidic to support life. Usage of significant amount of water for steam generating or cooling in conventional electricity production create imbalance in underground water. Flood, tropical cyclones, droughts, storm surges are most likely to become frequent and severe in coming years and will make in more difficult to achieve the Millennium Development Goal (MDG) [16].

\section{Social Impacts of Energy Deficiency}

Electricity is a pre-requisite for the technological development as well as the economic growth of a nation [17]. It is the cornerstone of ensuring energy security for any country. Around $42 \%$ people of Bangladesh earn below $\$ 1$ per day [18]. In order to change this scenario, reducing electricity crisis is one of the main pre-requisites. Countries that are lower in per capita energy consumption usually have low adult literacy rates, lower life expectancies and a low education index [19]. Human development index of Bangladesh is only 0.52 (on a scale of 0 to 1 ) with its $144 \mathrm{kWh}$ annual per capita energy usage, where Malaysia and Singapore are over 0.8 on that index with their $2300 \mathrm{kWh} 8200 \mathrm{kWh}$ per capita energy usage respectively [20]. In remote areas of Bangladesh especially in the hilly regions, the health, education and communication system are in deteriorating condition because of the unavailability of electricity. In this context, energy deficiency is one of the main barriers that hinder poverty alleviation, industrial and economical advancement, empowerment, and rural development.

\section{Prospect of Renewable Energy and Required Investment in Bangladesh}

Having the huge prospects of solar, wind, biogas and biomass, micro and mini hydro and tidal energy to harness and transform Bangladesh government has already targeted to generate $5 \%$ of total electricity from renewable energy by 2015 and $10 \%$ by 2020 . From only biogas and biomass, there is a potential to generate $800 \mathrm{MW}$ and $400 \mathrm{MW}$ of electricity respectively [6]. By setting micro $(<100 \mathrm{~kW})$ and mini $(<1000 \mathrm{~kW})$ hydro power plants in hilly area it is possible to get $20 \mathrm{MW}$ of electricity by 2020 [21]. According to [21], $250 \mathrm{MW}$ and $300 \mathrm{MW}$ of electricity generation is possible from hydro and $376 \mathrm{MW}$ and $1480 \mathrm{MW}$ of electricity generation is possible to harness from solar energy by 2015 and 2020 respectively. In addition, from biomass and biogas, it is possible to get $60 \mathrm{MW}$ and $120 \mathrm{MW}$ by 2015 and 2020, respectively, where from wind, it is possible to get $6 \mathrm{MW}$ and $100 \mathrm{MW}$, respectively. Tidal power prospect is about $4.57 \mathrm{MW}$ in Bangladesh [22]. However, new large-scale hydro power plant is not feasible due to its adverse effects on environment and biodiversity. In addition, extensive feasibility assessment is required before we go for geothermal-based electricity generation.

Bangladesh government has already formulated the Renewable Energy Policy and trying to attract investments from both indigenous and foreign investors by offering various incentives. In this section, we have presented an estimation of the total investment required in renewable energy sector of Bangladesh. Table 1 lists the country wise generation and investment in renewable energy sector in 2010. From Table 1, we have selected the countries from Asian region in order to facilitate the estimation of the investment required for Bangladesh. The selected countries are India, China, Indonesia, Japan, and South Korea, where the renewable energy investment for per MW electricity generation are $0.214,0.528,0.247,0.135$, and 0.297 million U.S. Dollar, respectively. These investments can be varied in terms of types of technologies used or government incentive support. By taking the average of investments in these countries, we roughly estimate that 0.284 million U.S. Dollar is needed for per MW electricity generation in Bangladesh. 
Table 1. Country wise generation and investment in renewable energy (RE) sector in 2010 [23].

\begin{tabular}{lccr}
\hline Country & $\begin{array}{c}\text { Total Investment } \\
\text { in RE (million \$) }\end{array}$ & $\begin{array}{c}\text { Installed } \\
\text { Capacity in MW }\end{array}$ & $\begin{array}{r}\text { Cost Per MW } \\
\text { Capacity } \\
\text { (million \$) }\end{array}$ \\
\hline Argentina & 743 & 600 & 1.238 \\
Australia & 3300 & 4000 & 0.825 \\
Brazil & 7600 & 14000 & 0.543 \\
Canada & 5600 & 7400 & 0.757 \\
China & 54400 & 103000 & 0.528 \\
France & 4000 & 9600 & 0.417 \\
Germany & 41200 & 49000 & 0.841 \\
India & 4000 & 18700 & 0.214 \\
Indonesia & 247 & 1000 & 0.247 \\
Italy & 13900 & 16700 & 0.832 \\
Japan & 3500 & 26000 & 0.135 \\
Mexico & 2300 & 2330 & 0.987 \\
Spain & 4900 & 27800 & 0.176 \\
South Korea & 356 & 1200 & 0.297 \\
Turkey & 1200 & 1420 & 0.845 \\
United Kingdom & 3300 & 7500 & 0.440 \\
United States & 34000 & 58000 & 0.586 \\
\hline
\end{tabular}

Therefore, in order to generate $687 \mathrm{MW}$ of electricity (5\% of total estimated electricity production by 2015) from renewable energy sources, investment of 196.5 million U.S. Dollar is required by 2015 , and to generate 2000 MW (10\% of total estimated electricity production by 2020) from renewable energy sources, investment of 371.5 million U.S. Dollar is required by 2020. Though it takes three to four times higher investment to generate renewable energy based electricity but if we take total life cycle cost by means of future fuel cost, future operation and maintenance cost, decommissioning costs and equipment lifetime on account, then investment in renewable energy is truly profitable. 38 billion U.S. Dollar has invested in renewable energy worldwide in 2005 and renewable energy is increasingly viewed as an attractive investment by private and public equity investors [24]. Moreover, investors would not be worried about the energy market in Bangladesh, as 58\% of total population has no electricity access [3].

Table 2. Estimated electricity generation and required investment.

\begin{tabular}{lcr}
\hline Sources & By 2015 (MW) & By 2020 (MW) \\
\hline Solar & 376 & 1480 \\
Hydro & 250 & 300 \\
Biomass and Biogas & 60 & 120 \\
Wind & 6 & 100 \\
Total Generation & 687 & 2000 \\
Total Investment Required & $\$ 196.5$ million & $\$ 371.5$ million \\
\hline
\end{tabular}

\section{Opportunities of Employment and GDP Growth}

Renewable energy creates more jobs per unit of energy produced and per dollar spent than fossil fuel technologies do. The ongoing trend to promote renewable energy based power generation indicates that it has tremendous job creation potential and has a direct impact on country's GDP growth. Solar industry creates 5.65 jobs and the wind energy creates 5.7 jobs per million U.S. Dollar investment. By contrast, coal industry creates only 3.96 jobs per million dollar investment [25]. As a major portion of renewable energy based electricity is expected to come from solar and wind (380 MW by 2015 and 1480 MW by 2020) [21], so 1500 and 3000 direct job opportunity would be available by 2015 and 2020 respectively. In addition, a large number of indirect job opportunities will be available by 2015 and 2020 if adequate investment is possible to attract in Bangladesh. This will surely be a relief for Bangladesh, as it has been suffering from 
unemployment problem with $4.8 \%$ unemployment rate [26]. In addition, we can be benefited by exporting skilled workers from this sector in overseas. This huge employment opportunity certainly will create a positive impact on GDP growth and give a pace to achieve double-digit GDP growth.

\section{Barriers in Promoting Renewable Energy Sector}

Although Bangladesh government has already formulated a Renewable Energy Policy in 2008, it has not been enacted as a law yet. Therefore, concerned authorities are not bound to meet up all the facility or targets that are promised to boost up renewable energy sector. Unavailability of relevant data and necessary information, lack of dedicated governmental Research \& Development (R\&D) wing, limited expertise on system design, installation, operation and maintenance of renewable energy technologies are the main barriers to promote renewable energy in Bangladesh. Bangladesh government is producing (including hydro $\sim 125$ MW from Kaptai plant) 127.43 MW ( $\sim 79 \%)$ of electricity, whereas the various Non-governmental organizations (NGOs) are contributing with $33.5 \mathrm{MW}$ ( $\sim 21 \%$, excluding hydro) using renewable sources [21]. However, if we consider the non-hydro electricity production then we will find that the government contribution in renewable energy sector is so poor in comparing with NGOs. Such poor participation of government often discourages investors to invest and take risk as it seemed non-profitable initially in renewable energy investment.

\section{Conclusion}

The whole world is now in a planetary emergency. In addition, as a third world country, Bangladesh has become the worst affected one. Therefore, we have to respond this critical problem quickly. Undoubtedly, renewable energy is the only sustainable solution of these acute problems. It can help us to get our energy security as a strong auxiliary force. Moreover, when we will be able to ensure the adequate investment to promote this sector then infrastructure development, job creation, women empowerment and poverty alleviation will happen automatically. Therefore, it is the high time to address energy insecurity immediately, take visionary planning, attract investment and create mass awareness. It is the policy makers' call to mobilize the whole nation through the right track.

It would not be an easy task to ensure about 200 million U.S. Dollar investments by 2015 and about 370 million U.S. Dollar by 2020 in renewable energy sector. However, as investment deals with available market and renewable energy technologies have become multi-billion dollar industry from the periphery of laboratories in recent years, it would not be too difficult to attract investment and find energy market as 82 million people have no electricity access in Bangladesh.

United Nations (UN) has already realized this energy insecurity problem and announced 2012 as the "International Year for Sustainable Energy for All" (Resolution 65/151). Therefore, as the citizens of UN, we all must be aware about renewable energy as a sustainable alternative to get rid of the curse of loadshedding and government must take drastic action for financing, technology transfer, associated policy making and institutional reforms to boost-up this sector and lead the nation to achieve the MDG through a sustainable way.

\section{References}

[1] Bangladesh Bureau of Statistics. (2011). Population Census Report. [Online]. Available: http://www.bbs.gov.bd/Home.aspx

[2] A. K. Hossain and O. Badr, "Prospects of renewable energy utilization for electricity generation in Bangladesh," Renewable \& Sustainable Energy Reviews, vol. 11, pp. 1617-1649, 2007.

[3] M. Jamaluddin, "SAARC regional trade study," Country Report-Bangladesh, 2008.

[4] International Energy Agency (IEA) Statistics Division. (2011). Energy and Resources—Electricity: Electricity Consumption per capita. [Online]. Available: http://earthtrends.wri.org/text/energy-resources/variable574.html

[5] Z. Choudhury. (2011). Natural Gas Reserve Estimate of Bangladesh. [Online]. Available: http://www.buet.ac.bd/dce/course_material/index.html

[6] I. Sharif, "Renewable Energy Development in Bangladesh," presented at Executive Exchange on the Use and Integration of Renewable Energy in the Power Sector, Madrid, Spain, 2009. 
[7] (2011). Energy Profile of Bangladesh. Encyclopedia of earth. [Online]. Available: http://www.eoearth.org/article/Energy_profile_of_Bangladesh

[8] (2006, Sep.). Developing renewables. Country Energy Information Bangladesh. [Online]. Available: http://www.energyrecipes.org/reports/genericData/Asia/061129\%20RECIPES\%20country\%20info $\% 20$ Bangladesh.pdf

[9] U. K. Rout, "Modeling of endogenous technology learning of energy technologies-an Analysis with a global multiregional energy system model," dissertation, University of Stuttgart, 2007.

[10] M. A. H. Mondal, "Implication of renewable energy technologies in the Bangladesh power sector: Long term planning strategies," Ph.D. thesis, Center for Development Research (ZEF), University of Bonn, Germany, Oct. 2010.

[11] T. Jilani, K. Gomi, and Y. Matsuoka, "Integration of sustainable and low carbon society towards 2025 in Bangladesh," in International Conference on Climate Change Effects and Energy Development in Bangladesh, Germany, Jul. 2011.

[12] A. U. Ahmed, Bangladesh Climate Change Impact and Vulnerability: A Synthesis. Department of Environment and Forestry, Government of Bangladesh, 2006.

[13] T. Islam and A. Neelim, "Assessing Fluctuations of Temperature," in Climate Change in Bangladesh: A Closer Look into Temperature and Rainfall Data. Bangladesh: The University Press Limited, 2010, pp. 80.

[14] A. Rahman, M. Alam, K. Mainuddin, L. Ali, S. M. Alauddin, M. G. Rabbani, M. M. U. Miah, M. RabiUzzaman, and S. M. A. Amin, "The probable impacts of climate change on poverty and economic growth and the options of coping with adverse effect of climate change in Bangladesh," Support to Monitoring PRS and MDGs in Bangladesh, Planning Commission, Government of the People's Republic of Bangladesh \& UNDP Bangladesh, May 2009.

[15] L. Hassan, "Climate change and food security: Sustainable agricultural production system for reducing food insecurity in Bangladesh," in International Conference on Climate Change Effects and Energy Development in Bangladesh, Germany, July 2011.

[16] Ministry of Environment and Forest, Bangladesh Climate Change Strategy and Action Plan 2008. Dhaka, Bangladesh: Government of the People's Republic of Bangladesh, 2008.

[17] A. H. Mondol, "Implications of renewable energy technologies in the Bangladesh power sector: Long term planning strategies," Doctoral Dissertation, Rheinischen Friedrich-Wilhelms-Universitat, 2010.

[18] UNDP, Population below International Poverty Lines in Asia, 2003. 2007.

[19] UNDP, Human Development Report 2007/2008. New York, NY: Palgrave Macmillan, 2007.

[20] UNDP, Human Development Index and Electricity Use in Asia and the Pacific, 1995 and 2002. 2006.

[21] D. M. Rahman, F. M. Mohammedy, A. R. Rume, and N. Nahar, "Prospects of renewable energy and its current status in Bangladesh," in International Conference on Climate Change Effects and Energy Development in Bangladesh, Germany, Jul. 2011.

[22] M. Rahman, M. M. I. Ullah, C. Ghosh, and F. M. Mohammedy, "The potential for implementation of tidal power in Bangladesh: a preliminary analysis," in International Conference on Climate Change Effects and Energy Development in Bangladesh, Germany, Jul. 2011.

[23] (2010, Mar. 25). Who is Winning the Clean Energy Race? G-20 Investment Powering Forward. [Online]. Available: http://www.pewenvironment.org/uploadedFiles/PEG/Publications/Report/G20Report-LOWRes-FINAL.pdf

[24] (2006, Sep.). American Energy: The Renewable Path to Energy Security. [Online]. Worldwatch Institute. Washington, DC. Available: http:// www.worldwatch.org/files/pdf/AmericanEnergy.pdf

[25] D. Kammen, K. Kapadia, and M. Fripp. (2004, Apr. 13). Putting Renewables to Work: How Many Jobs Can the Clean Energy Industry Create? Renewable and Appropriate Energy Laboratory (RAEL), UC Berkeley. [Online]. Available: http://rael.berkeley.edu/files/2004/Kammen-Renewable-Jobs2004.pdf

[26] Central Intelligence Agency. (2011). The World Factbook. [Online]. Available: http://www.cia.gov 